\title{
Abundance and diversity of Planctomycetes in a Tyrrhenian coastal system of central Italy
}

\author{
Ilaria Pizzetti ${ }^{1,2}$, Angélique Gobet ${ }^{3}$, Bernhard M. Fuchs ${ }^{1}$, Rudolf Amann ${ }^{1}$, \\ Stefano Fazi ${ }^{2, *}$ \\ ${ }^{1}$ Max Planck Institute for Marine Microbiology, Celsiusstr. 1, 28359 Bremen, Germany \\ ${ }^{2}$ Water Research Institute (IRSA-CNR), via Salaria km 29.300, 00015 Monterotondo, Roma, Italy \\ ${ }^{3}$ Station Biologique de Roscoff, UMR 7144, CNRS et Université Pierre et Marie Curie (UPMC), Place Georges Teissier, \\ 29680 Roscoff, France
}

\begin{abstract}
The phylum Planctomycetes is involved in important processes, such as the mineralization of algal biomass and the removal of nitrogen. Using a combination of 16S rRNA sequence analysis and in situ hybridization, we analyzed the diversity and dynamics of Planctomycetes in a shallow meso-eutrophic lake, Lago di Paola, Italy. Planctomycetes detected by the probe PLA46 accounted for 1 to $5 \%$ of prokaryotic picoplankton. Abundances were higher in the coastal lake than in the adjacent marine waters. In the surface waters of the lake, the numbers of Planctomycetes fluctuated greatly, reaching a maximum of $1.5 \times 10^{6} \mathrm{cells} \mathrm{ml}^{-1}$ in July. The hypoxic bottom waters had less variable cell abundances. The Planctomycetes counts were positively correlated with chlorophyll a concentrations, confirming the role of this phylum in the degradation of algal biomass. We obtained 70 almost full-length 16S rRNA gene sequences of Planctomycetes from 2 libraries. Four distinct clades could be identified. The Pirellula-related group F and the uncultured Planctomycetes group B both had the highest identity with sequences retrieved from marine habitats, whereas the Pirellula-related group E was affiliated with sequences known from freshwater and brackish water environments. The Planctomyces-related group A seems to have a wide habitat range. Catalyzed reported deposition fluorescence in situ hybridization with newly developed probes revealed abundances of the 4 clades in surface and bottom waters ranging from $1 \times 10^{3}$ to $5 \times 10^{4}$ cells $\mathrm{ml}^{-1}$. Together, the 4 clade-specific probes identified only about a quarter of the Planctomycetes detected by probe PLA46. This indicates that the diversity of Planctomycetes has not yet been fully explored.
\end{abstract}

KEY WORDS: Coastal lake ecology · Planctomycetes $\cdot$ Bacterial diversity $\cdot$ FISH $\cdot$ CARD-FISH · 16S rRNA gene sequencing

\section{INTRODUCTION}

Planctomycetes are a phylum of budding bacteria with a peptidoglycan-free proteinaceous cell wall of increasing interest for ecology, genomics and, particularly, cell biology and microbial evolution (Fuerst 1995). Their most distinctive feature is an internal compartmentalization (Lindsay et al. 1997, 2001,
Fuerst 2005), which is reminiscent of the eukaryotic lineage (Fuerst 2005). They are part of the Planctomycetes/Verrucomicrobia/Chlamydiae superphylum, which, in addition to Planctomycetes, includes the phyla Verrucomicrobia, Chlamydiae and Lentisphaerae, and the candidate phyla Poribacteria and OP3 which do not yet have any culture representatives (Fieseler et al. 2004, Wagner \& Horn 2006). 
Most cultured strains have been isolated from marine, freshwater and terrestrial habitats (Bauld \& Staley 1976, Franzmann \& Skerman 1984, Giovannoni et al. 1987, Schlesner 1994, Wang et al. 2002). Despite the recent success in isolating new members of the Planctomycetes from aquatic (Fukunaga et al. 2009, Winkelmann \& Harder 2009) and terrestrial habitats (Kulichevskaya et al. 2007, 2008, 2009), the phylum continues to be one of the least represented in microbial culture collections. Planctomycetes are most commonly heterotrophs (Fuerst 1995), with the notable exception being the autotrophic anammox bacteria, which catalyze anaerobic ammonia oxidation with nitrite (Strous et al. 1999).

Studies based on molecular methods, such as $16 \mathrm{~S}$ ribosomal RNA (rRNA) gene sequencing and fluorescence in situ hybridization (FISH), have revealed a broad distribution of Planctomycetes in aquatic environments. They have been detected in the marine water column (DeLong et al. 1993, Vergin et al. 1998, Shu \& Jiao 2008a), where they often colonize marine snow particles (DeLong et al. 1993, Rath et al. 1998, Crump et al. 1999), in marine sediments (LlobetBrossa et al. 1998, Rusch et al. 2003, Inagaki et al. 2006, Musat et al. 2006, Shu \& Jiao 2008c) and in the water column and sediments of freshwater systems (Neef et al. 1998, Miskin et al. 1999, Kalyuzhnaya et al. 2004, 2005, Amalfitano et al. 2008). Many studies have reported high abundances of Planctomycetes following algal blooms (Janse et al. 2000, Brümmer et al. 2004, Eiler \& Bertilsson 2004, Ward et al. 2006, Tadonléké 2007, Pizzetti et al. 2011). Morris and coworkers (Morris et al. 2006) found that high abundances of Pirellula-related cells (up to $4 \times 10^{4} \mathrm{ml}^{-1}$ ) occurred during a diatom bloom in Oregon coastal waters. Furthermore, genomic and metagenomic evidence indicates the specialization of marine Planctomycetes for algal polymer degradation (Glöckner et al. 2003, Woebken et al. 2007b). Recent studies have shown the presence of Planctomycetes in the Venice Lagoon (Simonato et al. 2010) and the Río de la Plata estuary (Alonso et al. 2010). An in-depth assessment of the diversity, abundance and distribution of coastal Planctomycetes has only recently been initiated for the North Sea (Pizzetti et al. 2011). Herein, we extend this study to a Mediterranean coastal lake. This is a meso-eutrophic aquatic environment representative of South European coastal systems for which no study focusing on the ecology of Planctomycetes has yet been performed.

The aim of this study was to analyze the abundance and diversity of Planctomycetes in a particular coastal system by using $16 \mathrm{~S}$ rRNA-based methods. Based on previous results obtained in the North Sea (Pizzetti et al. 2011), we hypothesized that Lago di Paola, with its meso-eutrophic character, would be particularly rich in Planctomycetes in terms of both abundance and diversity.

\section{MATERIALS AND METHODS}

\section{Study area, sample collection and processing}

Lago di Paola is a shallow, meso-eutrophic lake located on the Tyrrhenian coast of Central Italy (Latium). It is part of a cluster of 4 coastal lakes (Fogliano, Paola, Caprolace and Monaci) and is characterized by a water residence time of 8 to 12 mo. Two narrow artificial channels at the northwestern and southeastern ends of the lake allow for a limited water exchange with the sea, which is enough to sustain a high degree of salinity throughout the year. Freshwater only enters the lake because of the intrusion of groundwater, which, in summer, is drastically reduced because of its exploitation for agricultural purposes. The lake has a surface area of $\sim 400$ ha (main axis $7 \mathrm{~km}$ ) and a mean depth of $4 \mathrm{~m}$, except in its central area, where a small depression reaching a depth of $10 \mathrm{~m}$ is located. The lake has been exploited for fish farming since the time of the Roman Empire.

Between January and December 2003, surface water samples were collected monthly (fortnightly in May, June and July) using a Niskin bottle at a depth of $\sim 50 \mathrm{~cm}$ from 3 stations along Lago di Paola's main axis. We have named these stations SAB1, SAB2 and SAB3 (Fig. 1). Samples were also taken from the marine coastal waters off the mouth of the lake outlet, $100 \mathrm{~m}$ from the shore line (SAB4) (Fig. 1). From July onwards (monthly, except September), samples were also collected from the trench that represents the deepest point in the lake ( 10 m; SAB2b).

The environmental parameters were ascertained as described by Manganelli (2005). Briefly, temperature, salinity, pH and dissolved oxygen (DO) were determined with probes (Wissenschaftlich-Technische Werkstätten; Kent Electronic Instrument). The analytical methods used for the determination of dissolved nutrients (phosphate, nitrate and nitrite) were those reported by Parsons et al. (1984) and Valderrama (1981). The dissolved organic carbon (DOC) concentration was analyzed by high temperature catalytic oxidation using a Shimadzu TOC-5000 analyzer (Pettine et al. 1999). Chlorophyll a (chl a) was extracted in $90 \%$ acetone and concentrations were measured by spectrophotometry according to Lorenzen (1967). 


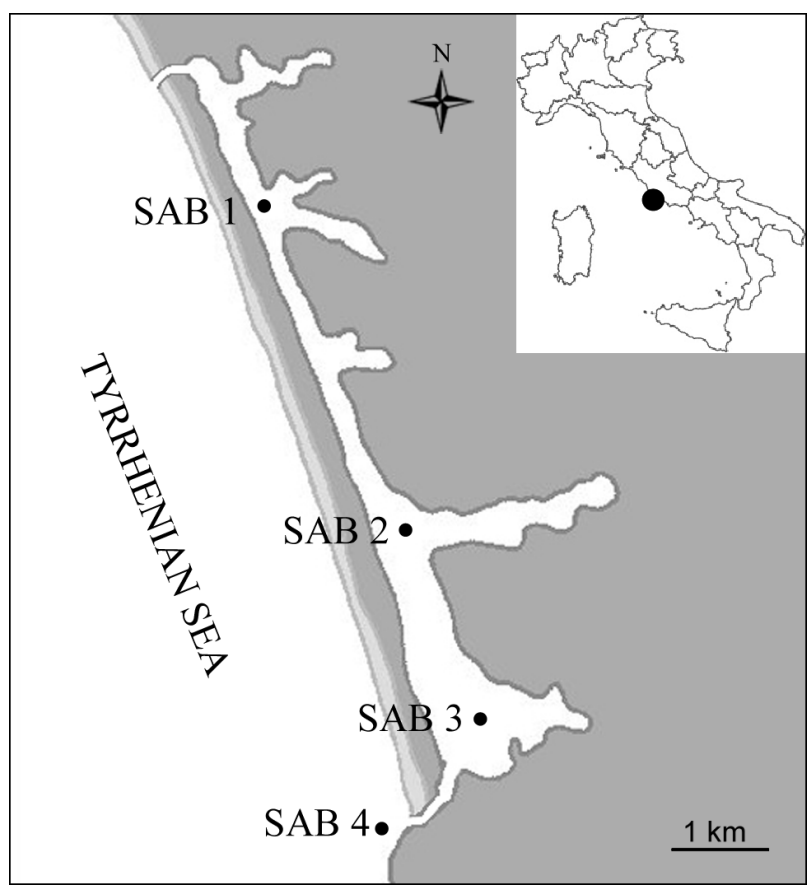

Fig. 1. Schematic map of the Lago di Paola indicating the 4 sampling sites. SAB1: $41^{\circ} 18^{\prime} 0.4^{\prime \prime} \mathrm{N}, 13^{\circ} 00^{\prime} 47.6^{\prime \prime} \mathrm{E}_{\text {; }} \mathrm{SAB} 2$ : $41^{\circ} 16^{\prime} 12.3^{\prime \prime} \mathrm{N}, 13^{\circ} 02^{\prime} 15.0^{\prime \prime} \mathrm{E}_{\text {; }} \mathrm{SAB} 3$ : $41^{\circ} 15^{\prime} 21.9^{\prime \prime} \mathrm{N}, 13^{\circ} 02^{\prime}$ $37.0^{\prime \prime} \mathrm{E}_{\text {; }} \mathrm{SAB} 4: 41^{\circ} 14^{\prime} 48.0^{\prime \prime} \mathrm{N}, 13^{\circ} 02^{\prime} 11.0^{\prime \prime} \mathrm{E}$

Starting in July, the abundance of the Planctomycetes was quantified by fluorescence in situ hybridization (FISH) and catalyzed reporter deposition (CARD)-FISH. Aliquots were fixed with formaldehyde (final concentration $2 \%$ ) for $1 \mathrm{~h}$ at room temperature and for up to $24 \mathrm{~h}$ at $4^{\circ} \mathrm{C}$. Thereafter, 4 to $10 \mathrm{ml}$ aliquots were filtered at a low vacuum level (200 mbar) onto $0.2 \mu \mathrm{m}$ pore-size polycarbonate filters (type GTTP; diameter, $47 \mathrm{~mm}$; Millipore). All of the filters were stored at $-20^{\circ} \mathrm{C}$ until further processing.

To analyze Planctomycetes diversity, additional sampling was carried out on 15 September 2008 at stations SAB2 and SAB2b. Temperature, salinity and DO were recorded during this process. Overall, the same procedures were followed as in 2003, except that the bacterial cell fixation for the FISH and CARD-FISH was performed with a paraformaldehyde solution $(20 \% \mathrm{w} / \mathrm{v}$, Electron Microscopy Sciences; final concentration $1 \%$ ), and the prefiltration of the water samples was through $10 \mu \mathrm{m}$ pore-size polycarbonate filters (type TCTP; diameter, $47 \mathrm{~mm}$; Millipore). Moreover, for the purposes of DNA isolation, aliquots of between 750 and $1250 \mathrm{ml}$ were filtered onto $0.2 \mu \mathrm{m}$ pore-size polycarbonate filters (type GTTP; diameter, $47 \mathrm{~mm}$; Millipore) after pre- filtration through $10 \mu \mathrm{m}$ pore-size polycarbonate filters (type TCTP; diameter, $47 \mathrm{~mm}$; Millipore). The filters were frozen semi-dry and kept at $-20^{\circ} \mathrm{C}$ until processed for nucleic acid extraction.

\section{FISH and CARD-FISH}

Planctomycetes abundance in both the 2003 and 2008 samples was quantified by FISH and CARDFISH with probe PLA46 (Neef et al. 1998), and the cell numbers obtained were then compared. All of the samples were also inspected for false-positive signals using the NON338 probe (Wallner et al. 1993). In the 2003 formaldehyde fixed samples ( $2 \%$ final concentration), the numbers of Planctomycetes cells after FISH were higher ( $43 \%$ more) than the numbers of cells obtained by CARD-FISH (Fig. S1 in the supplement at www.int-res.com/articles/suppl/ a065p129_supp.pdf). No false-positive signals were detected in any of the samples. Consequently, the Planctomycetes in the 2003 sample were further quantified by FISH. Conversely, the Planctomycetes in the 2008 samples fixed with paraformaldehyde solution ( $1 \%$ final concentration) were quantified by CARD-FISH, because this approach yielded higher probe-positive cell numbers than was the case for the FISH preparations (Fig. S1). No false-positive signals were detected in these samples by CARD-FISH.

FISH was performed according to the protocol of Glöckner et al. (1996). CARD-FISH was also performed using the same 2 probes according to the protocols established by Pernthaler et al. $(2002,2004)$ and slightly modified by Pizzetti et al. (2011) to improve the fluorescence signals of the Planctomycetes. The samples were permeabilized with lysozyme (10 $\mathrm{mg} \mathrm{ml}^{-1}$; Fluka; buffer contained 0.05 M EDTA, $\mathrm{pH} 8,0.1 \mathrm{M}$ Tris- $\mathrm{HCl}, \mathrm{pH} 7.4$ ) for $1 \mathrm{~h}$ at $37^{\circ} \mathrm{C}$ and then with achromopeptidase $\left(60 \mathrm{U} \mathrm{ml}^{-1}\right.$; Sigma; buffer contained $0.01 \mathrm{M} \mathrm{NaCl}, 0.01 \mathrm{M}$ Tris- $\mathrm{HCl}, \mathrm{pH}$ 8.0) for $30 \mathrm{~min}$ at $37^{\circ} \mathrm{C}$. Additionally, hybridization was performed at $46^{\circ} \mathrm{C}$ for $2.5 \mathrm{~h}$ with a washing step at $48^{\circ} \mathrm{C}$ for $5 \mathrm{~min}$. Filter sections, counterstained with 4',6-diamidino-2-phenylindole (DAPI; final concentration $1 \mu \mathrm{g} \mathrm{ml}^{-1}$ ) and washed for $1 \mathrm{~min}$ in Milli-Q water and $96 \%$ ethanol, were subsequently arranged on microscope slides and embedded in a mixture of 2 anti-fading re-agents (VECTASHIELD ${ }^{\circledR}$ Mounting Medium H-1000, Vector Laboratories and Citifluor [1:5]). The slides were stored at $-20^{\circ} \mathrm{C}$ until further analysis, and the cells were quantified on an Axioplan II Imaging epifluorescence microscope (Zeiss). 


\section{DNA extraction and PCR amplification}

Total nucleic acids were extracted according to the protocol established by Zhou et al. (1996) and slightly modified by Pizzetti et al. (2011). Picoplankton samples were collected by filtration from the surface (SAB2) and the bottom waters of the lake (SAB2b) (Fig. 1).

Fragments of $\sim 1.4 \mathrm{~kb}$ in size, encompassing almost full-length 16S rRNA genes, were amplified using both the primer PLA46F (5'-GGA TTA GGC ATG CAA GTC-3', targeting position 46-63 on the $16 \mathrm{~S}$ rRNA gene; Neef et al. 1998), specific for Planctomycetes, and the general primer, 1392R (5'-ACG GGC GGT GTG TAC-3', targeting Escherischia coli position 1392-1406 on 16S rRNA gene; Xu et al. 1998). Each PCR reaction was carried out with a $50 \mu$ master mix including: $0.3 \mathrm{mg} \mathrm{ml}^{-1} \mathrm{BSA}$ (final concentration; Sigma Chemie); $1 \times$ reaction buffer (final concentration; Eppendorf); $0.25 \mathrm{mM}$ dNTPs (final concentration; Roche Diagnostics); $0.5 \mu \mathrm{M}$ for each primer (final concentration; http://Biomers.net);

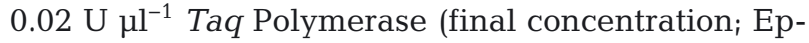
pendorf); and $1 \mu \mathrm{l}$ DNA. The PCR was run with the following cycling conditions: an initial denaturation step at $94^{\circ} \mathrm{C}$ for $4 \mathrm{~min} ; 33$ cycles of 1 min denaturation at $94^{\circ} \mathrm{C} ; 2 \mathrm{~min}$ annealing at $59^{\circ} \mathrm{C}_{i} 1.5 \mathrm{~min}$ elongation at $72^{\circ} \mathrm{C}$; and a final extension step of $10 \mathrm{~min}$ at $72^{\circ} \mathrm{C}$. The PCR cycle numbers were reduced as much as possible, while 10 replicates were processed in parallel to minimize PCR bias (Suzuki \& Giovannoni 1996, Polz \& Cavanaugh 1998). Finally, the PCR products were checked in a $1 \%$ agarose gel electrophoresis (Biozym LE agarose).

\section{S rRNA gene libraries, sequencing and phylogenetic reconstruction}

The PCR product was purified by agarose gel electrophoresis, and the $1.4 \mathrm{~kb}$ band was excised and purified using a Qiaquick Gel extraction kit (QIAGEN). Purified amplicons were ligated in vector P-GEM T-Easy (Promega) according to the manufacturer's instructions. The recombinant plasmids were then transformed into chemically competent Escherichia coli cells (Invitrogen), plated and picked. Plasmid DNA was isolated with the Montage ${ }^{\text {TM }}$ Plasmid Miniprep Kit (Millipore). It was then sequenced using the 2 vector primers, M13F (5'-GTA AAA CGA CGG CCA G-3') and M13R (5'-CAG GAA ACA GCT ATG AC-3'), as well as the primer GM1F (5'-CCA GCA GCC GCG GTA AT-3'; Lane 1991), to obtain almost full-length 16S rRNA gene sequences. Contigs were assembled using the SEQUENCHER software Version 4.6 (Gene Codes Corporation). The 16S rRNA gene sequences were subsequently deposited in the EMBL Nucleotide Sequence Database with the accession numbers FR714331 to FR714400.

The sequences were aligned in the ARB software package (www.arb-home.de; Ludwig et al. 2004) using the SINA_aligner (Pruesse et al. 2007). The alignments were further refined manually by conducting a comparison with their closest relatives. For the in-depth phylogenetic rRNA analysis, only sequences with >1200 nucleotides were included. The phylogenetic tree reconstruction was based on the distance matrix (e.g. neighbor-joining) and maximum likelihood methods with and without 30 and $50 \%$ Planctomycetes positional conservatory filters, respectively. The Verrucomicrobia, Lentisphaerae, Chlamydiae and Candidatus OP3 sequences were used as out-groups. A consensus tree was then constructed (Peplies et al. 2008).

The diversity coverage of the sequenced clones was analyzed using the computer program DOTUR (distance-based operational taxonomic unit [OTU] and richness; Schloss \& Handelsman 2005). OTUs were calculated using the furthest neighbor algorithm for each distance level, from a distance matrix generated in ARB. To construct the rarefaction curves, we then selected $97 \%$ (species level) and 95\% (genus level) sequence identities, as reported by Rosselló-Mora \& Amann (2001). The coverage index $(C)$ of the clone libraries was calculated with the formula $C=(1-n / N) 100$, where $N$ is the number of all of the clones with a Planctomycetes insert and $n$ the number of phylotypes at a 97 and $95 \%$ identity level appearing only once in the library (Good 1953, Kemp \& Aller 2004).

\section{Probe design}

Using the ARB software's probe design tool, oligonucleotide probes targeting the 16S rRNA of the Planctomycetes clades were designed based on the newly created phylogenetic tree. Probe specificities were checked in silico against the SILVA 16S rRNA database (version 100; Pruesse et al. 2007) (Table S1 in the supplement at www.int-res.com/articles/suppl/ a065p129_supp.pdf). To optimize the stringency conditions, a series of hybridizations at increasing formamide concentrations (10 to $60 \%$ ) were evaluated in appropriate natural samples. The optimal formamide concentration was the highest concentration 
before the signal intensity started to decrease (Table S2 in the supplement). Probes were applied for the CARD-FISH performed on the 2008 samples.

\section{Statistics}

Multiple linear correlations between Planctomycetes absolute abundance and environmental parameters (salinity, temperature, DO, $\mathrm{pH}, \mathrm{chl} a, \mathrm{DOC}_{1} \mathrm{PO}_{4}{ }^{3-}$, $\mathrm{NO}_{2}{ }^{-}$, and $\mathrm{NO}_{3}{ }^{-}$) were firstly calculated using the Spearman rank correlation test and the p-value was Bonferroni corrected to test for multiple comparisons (Legendre \& Legendre 1998).

The partial least squares regression (PLSR) was then applied to model the relationship between Planctomycetes absolute abundances ( $Y$-response variables) and physico-chemical parameters ( $X$-descriptive variables; here: salinity, temperature, DO, $\mathrm{pH}$, chl a, DOC, $\mathrm{PO}_{4}{ }^{3-}, \mathrm{NO}_{2}{ }^{-}$, and $\mathrm{NO}_{3}{ }^{-}$). Descriptive variables were log transformed and normalized before analysis (means were centered to 0 and the variables were standardized by dividing each of them by their standard deviation). This robust method generalizes multiple linear regression by analyzing data with strongly collinear, correlated, noisy and many $X$ descriptive variables, and can simultaneously model several $Y$-response variables, also in cases of incomplete data sets (Wold et al. 2001).

Statistical analyses were carried out using Sigma Stat 3.5 (Systat Software) and the R statistical environment ( $\mathrm{R}$ version 2.10.0; R Development Core Team 2009), including the pls package (Mevik \& Wehrens 2007) and custom R scripts.

\section{RESULTS}

\section{Physico-chemical parameters}

During 2003, the environmental parameters within the lake displayed remarkable seasonal variability in comparison to those registered in the neighboring marine coastal waters (Fig. 2). Indeed, the salinity values ranged between 29.0 (March) and 38.0 (August) in the lake, and between 37.5 (February) and 39.0 (September) in the marine waters (Fig. 2). Oxygen saturation in the lake fluctuated greatly throughout the year, with the highest value registered in May (162\%) and the lowest in August (37\%). In the coastal marine waters, these values ranged between $73 \%$ in September and $114 \%$ at the beginning of May (Fig. 2).
At the beginning of July, the water column was stratified, as indicated by a steep gradient in temperature $\left(29.1^{\circ} \mathrm{C}\right.$ surface; $24.8^{\circ} \mathrm{C}$ bottom). Indeed, the oxygen saturation values at that time were 131 and $27 \%$ in the surface and bottom waters, respectively (Fig. 3A). In August, the water masses started to remix, with homogeneous temperature values for surface and bottom waters $\left(\sim 28^{\circ} \mathrm{C}\right)$. Salinity was $\sim 38$ through the entire water column and the hypoxia extended from the bottom waters (13\% oxygen) into the surface waters (35\% oxygen) (Fig. 3A). At that time, low oxygen concentrations were observed along the entire lake $(\mathrm{SAB} 1=38 \%$ and $\mathrm{SAB} 3=39 \%)$, and the oxygen in the surface waters remained low, including in September. In the months that followed, however, oxygen concentrations increased in both the surface and the bottom waters.

\section{Microbial and Planctomycetes abundance in 2003}

In the lake, the absolute numbers of prokaryotic picoplankton in the surface waters ranged between 6.2 $\times 10^{6} \mathrm{ml}^{-1}$ in December at SAB3 and $3.4 \times 10^{7} \mathrm{ml}^{-1}$ in July at SAB2 (Table S3 in the supplement). In the deeper layers, the cell numbers ranged between $8.9 \times$ $10^{6} \mathrm{ml}^{-1}$ in December and $2.1 \times 10^{7} \mathrm{ml}^{-1}$ in July (Table S3). Meanwhile, in the marine coastal waters, the absolute cell counts ranged between $9.1 \times 10^{5} \mathrm{ml}^{-1}$ in September and $4.7 \times 10^{6} \mathrm{ml}^{-1}$ in July (Table S3). Overall, the mean cell numbers of prokaryotic picoplankton in the lake $\left(1.8 \times 10^{7} \mathrm{ml}^{-1}\right)$ were 7.7 -fold higher compared with what was found at a nearshore sampling site in the adjacent Tyrrhenian Sea $\left(2.3 \times 10^{6} \mathrm{ml}^{-1}\right)$.

The relative abundance of Planctomycetes at SAB1 was at its highest at the beginning of July, representing $4.7 \pm 0.4 \%$ (mean $\pm \mathrm{SD}$ ) of the prokaryotic picoplankton community. This decreased to $0.8 \pm 0.5 \%$ in September (Fig. 4, Table S3). In October, the percentage increased to $1.9 \pm 0.2 \%$ and remained at almost the same level in November $(1.4 \pm 0.6 \%)$ and December $(1.8 \pm 1.1 \%)$. At SAB2, Planctomycetes abundance increased between the beginning (1.5 \pm $0.4 \%$ ) and the end of July $(5.4 \pm 2.1 \%$ ) (Figs. $3 b$ \& 4 , Table S3). Indeed, the highest abundances of Planctomycetes were registered at the end of this month. Planctomycetes abundance then decreased to $0.8 \pm$ $0.2 \%$ in September, increased to $2.8 \pm 0.7 \%$ in October and then fell slightly to $1.5 \pm 0.7 \%$ in December. Relative abundances at the bottom of SAB2 were more stable, ranging between $1.4 \pm 0.9 \%$ in October and $2.1 \pm 0.4 \%$ in August (Fig. 3B). Planctomycetes relative abundance at SAB3 increased from $1.8 \pm 0.2$ 

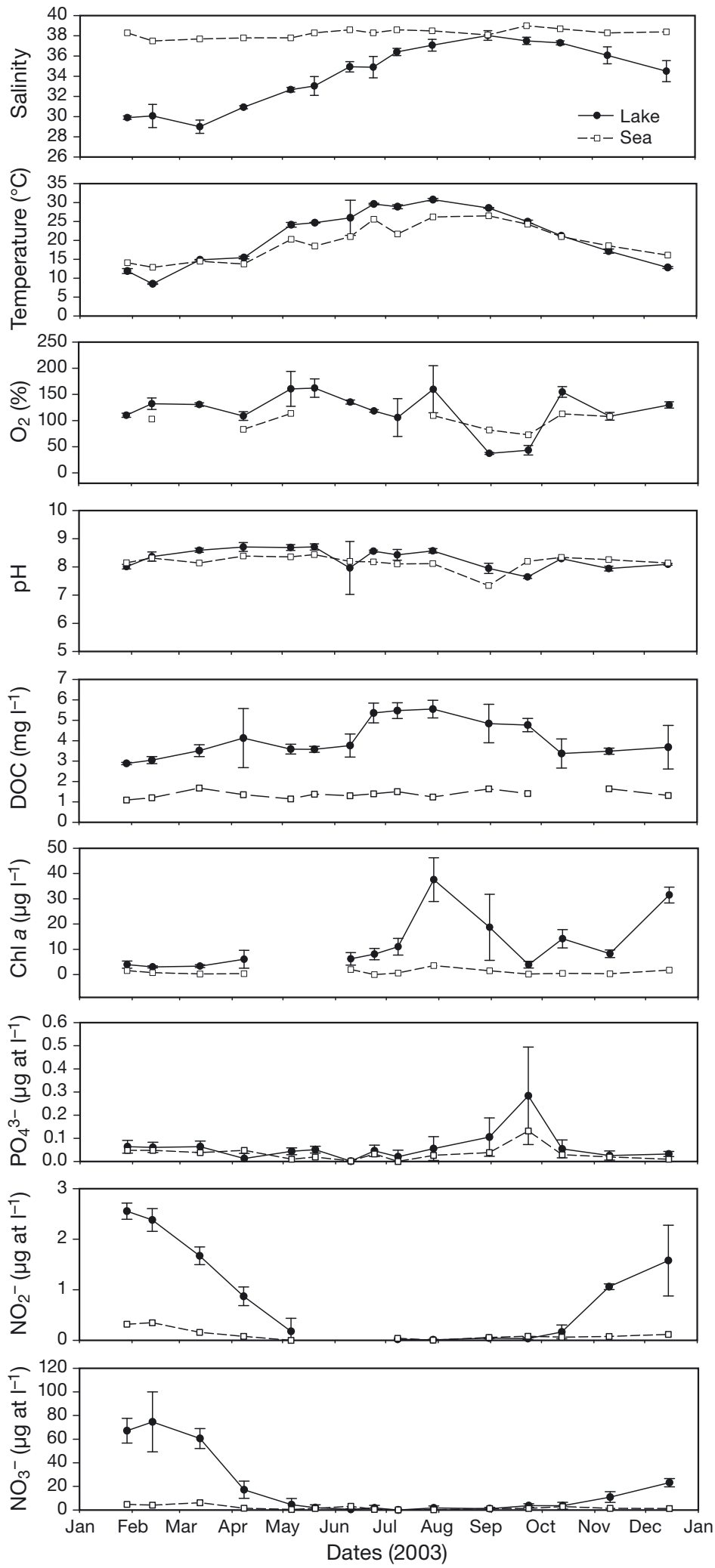

Fig. 2. Environmental parameters collected between January and December 2003. Modified from Manganelli (2005). Means of SAB1, SAB2 and SAB3 (see Fig. 1) values ( \pm SD) are shown. For a few time points no data were recorded (gaps). DOC: dissolved organic carbon to $3.4 \pm 3.4 \%$ between the beginning and the end of July and decreased to $0.9 \pm 0.6 \%$ in August. There was then an increasing trend until October $(3.2 \pm 1.4 \%)$. Thereafter, the abundance decreased to $2.0 \pm 0.3 \%$ in December. Generally, the highest abundances of Planctomycetes in the lake were registered in July and October (Fig. 4, Table S3). In the neighboring marine coastal waters (SAB4), relative abundance increased from $0.8 \pm 0.3 \%$ in July to $2.0 \pm$ $0.8 \%$ in September, before decreasing to 0.9 $\pm 0.2 \%$ in December (Fig. 4, Table S3). Overall, mean Planctomycetes relative abundance was 1.6-fold higher in the lake than in the sea.

Correlation analyses revealed that the absolute abundances of Planctomycetes were significantly correlated with chl a $(\mathrm{n}=$ $\left.28, \mathrm{r}_{\mathrm{S}}=0.65, \mathrm{p} \leq 0.001\right)$, DOC $\left(\mathrm{r}_{\mathrm{S}}=0.62, \mathrm{p} \leq\right.$ $0.001)$, salinity $\left(\mathrm{r}_{\mathrm{S}}=-0.56, \mathrm{p} \leq 0.01\right)$, oxygen $\left(\mathrm{r}_{\mathrm{S}}=0.48, \mathrm{p} \leq 0.05\right)$ and $\mathrm{pH}\left(\mathrm{r}_{\mathrm{s}}=0.38, \mathrm{p} \leq\right.$ 0.05). No significant correlations with temperature, $\mathrm{PO}_{4}{ }^{3-}, \mathrm{NO}_{3}{ }^{-}$or $\mathrm{NO}_{2}{ }^{-}$were found (Table S4 in the supplement).

A PLSR was performed to elucidate the main relationships between the variance of Planctomycetes abundance ( $Y$ variable) and physico-chemical variables ( $X$ variables). The first 2 latent variables (LV 1 and 2) of the model explained 50 and $8 \%$ of the total variation in the $Y$ variable, respectively (Fig. S2 in the supplement). The score plot indicates environmental conditions and seems to induce a grouping of samples according to sampling months or sampling sites (Fig. S2A). Indeed, July samples are separated from other samples along the LV 1 axis (dark blue circle, Fig. S2A), and August and September samples seem to be separated from other samples along the LV 2 axis (pink circle, Fig. S2A). Samples from site SAB4 also grouped together, validating conditions from this coastal offshore site, different from the other sites in the lake. LV 1 explained $23 \%$ of the variation in the environmental variables and was positively influenced mostly by $\mathrm{pH}$, chl $a$, temperature and DOC and negatively influenced by salinity, nitrite and nitrate (Fig. S2B). Also, $11 \%$ of the variation in the environmental variables was explained by LV 2, which was mostly positively influ- 

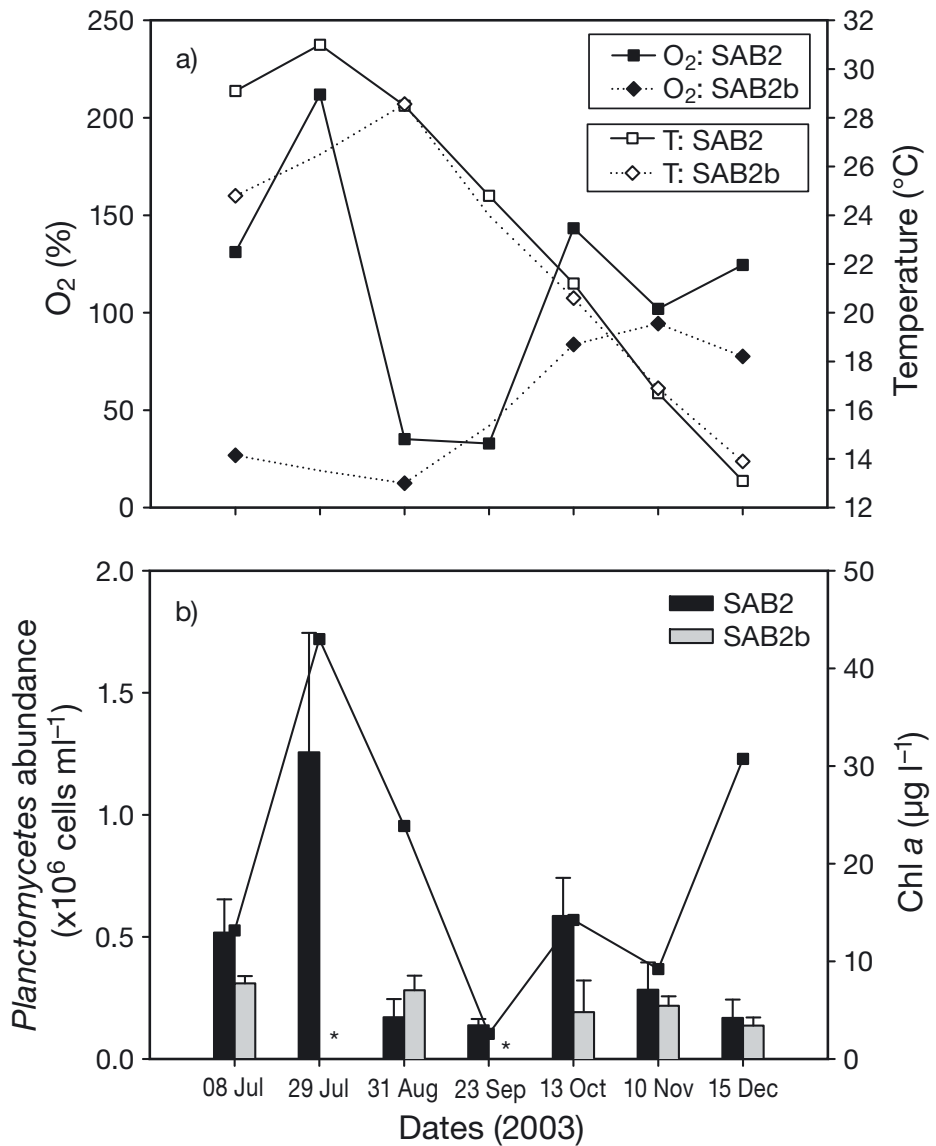

Fig. 3. (A) Oxygen and temperature and (B) Planctomycetes absolute counts at the surface (SAB2) and the bottom (SAB2b) of the Lago di Paola at the 7 sampling days between July and December 2003. Means \pm SD of 3 replicates are shown. Chl a values registered at SAB2 are shown. ${ }^{*}$ Sampling not done

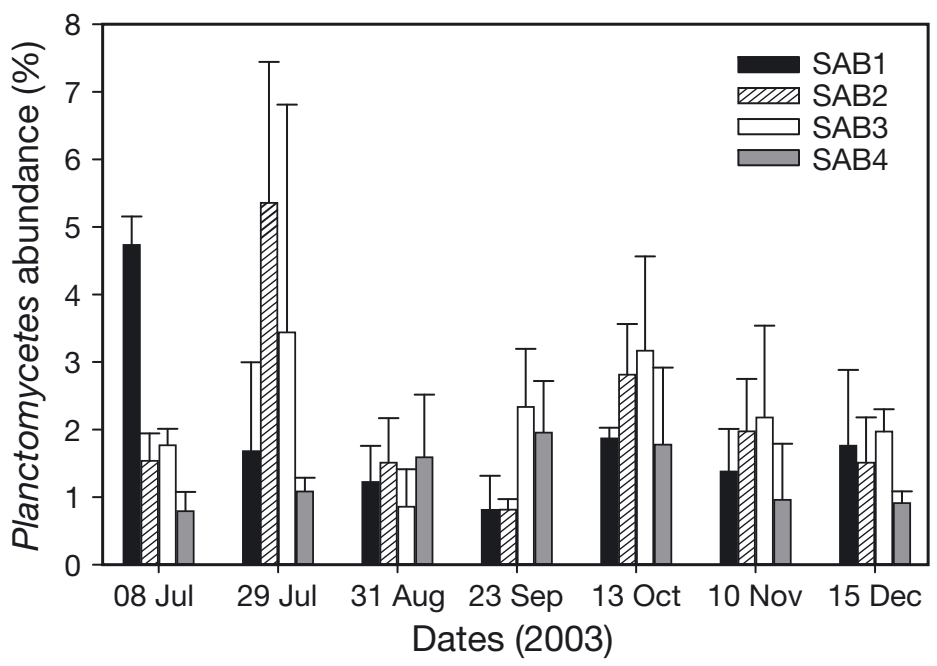

Fig. 4. Planctomycetes relative abundances at the 3 sampling sites along the lake (see Fig. 1) and at the adjacent marine waters between July and December 2003. Relative abundances were calculated by comparison to DAPI-stained cells. Means \pm SD of 3 replicates are shown enced by DO and nitrite, and negatively influenced by temperature and DOC. Planctomycetes abundance was situated on the positive part of both latent variables, and thus seems to be mostly linked to $\mathrm{chl} a, \mathrm{DOC}, \mathrm{pH}$, water column temperature, and DO and nitrite.

\section{Diversity of Planctomycetes}

Two clone libraries were constructed from the surface (SAB2) and bottom waters (SAB2b) sampled on 15 September 2008, using a primer pair targeting the 16S rRNA genes of Planctomycetes (PLA46F/1392R). PLA46 currently has a group coverage of $52 \%$, and is fully complementary to 1903 of the 3645 Planctomycetes 16S rRNA sequences. It also has some outgroup hits, most of which are within the Lentisphaerae. On 15 September, temperature $\left(26.0^{\circ} \mathrm{C}\right)$ and salinity (37.1) did not vary over depth, and hypoxic conditions were observed in both the surface $(21 \%)$ and the bottom waters $(12 \%)$. The percentage of Planctomycetes determined by CARD-FISH was (mean $\pm \mathrm{SD}) 3.4 \pm 0.1 \%\left(2.8 \pm 0.09 \times 10^{5} \mathrm{ml}^{-1}\right)$ at the surface of Lago di Paola and $5.2 \pm 0.6 \%$ (3.6 \pm $0.4 \times 10^{5} \mathrm{ml}^{-1}$ ) at the bottom. In total, we analyzed 161 sequences, of which 101 were affiliated with Planctomycetes. Forty of 83 sequences retrieved from SAB2 were affiliated to Planctomycetes, 21 to Chlamydiae, 16 to Lentisphaerae, 4 to Verrucomicrobia and 2 to the candidate division OP3. Of the 78 sequences, 61 retrieved from the SAB2b sequences belonged to the Planctomycetes, 11 to Lentisphaerae, 5 to Chlamydiae and 1 to the candidate division OP3. We were able to determine almost full-length sequences for 70 of the 101 Planctomycetes clones.

Comparative sequence analyses enabled us to distinguish 4 phylogenetic clades. These were named: Pirellula-related group $F_{\text {, }}$ Pirellula-related group E, uncultured Planctomycetes group B and Planctomyces-related group A (Fig. 5). These clades remained stable in different types of tree reconstructions (neighbor-joining, maximum likelihood) with and without Planctomycetes positional conservatory filters (50 and $30 \%$, respectively).

The Pirellula-related group F sequences accounted for 3 of 31 of the almost full-length Planctomycetes sequences obtained in this 


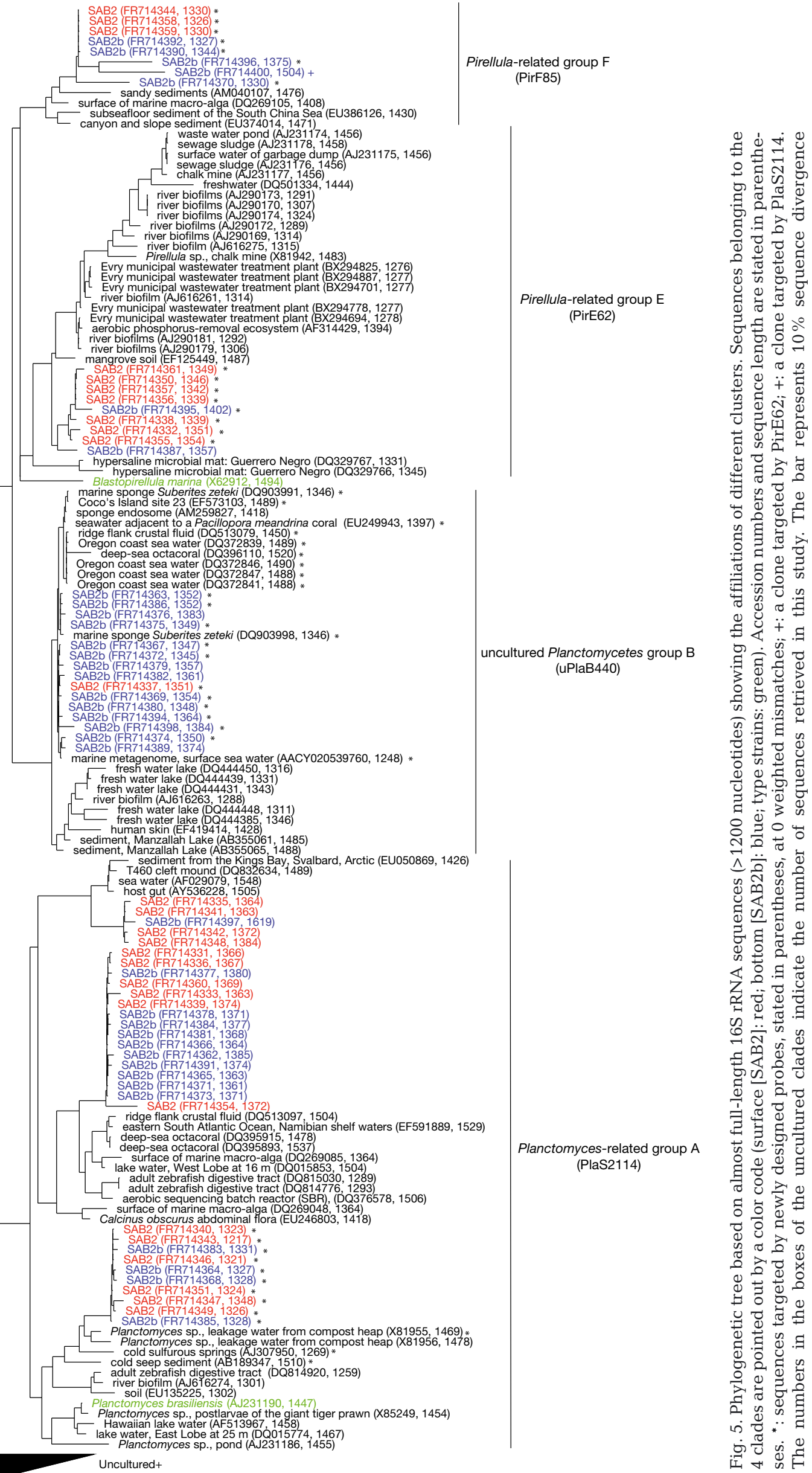


study from the surface water (SAB2), and 5 of 39 found in the bottom water (SAB2b). The sequences shared $\sim 86 \%$ sequence identity with Blastopirellula marina (Fig. 5). The frequencies of the Pirellularelated group E were $7 / 31$ and 2/39 in SAB2 and $\mathrm{SAB} 2 \mathrm{~b}$, respectively. The sequences in this clade shared $\sim 89 \%$ sequence identity with $B$. marina and $\sim 87 \%$ with a strain of the genus Pirellula (Fig. 5). The sequences from the uncultured Planctomycetes group B were retrieved much less frequently from SAB2 (1/31) than from SAB2b (14/39) (Fig. 5), whereas the Planctomyces-related group A appeared frequently in both libraries (16/31 in SAB2 and 15/39 in SAB2b). The former group shared $\sim 87 \%$ sequence identity with Planctomyces brasiliensis, whereas for the latter this was between 85 and $87 \%$ with strains of the genus Planctomyces (Fig. 5).

The coverage of Planctomycetes diversity at SAB2 was $84 \%$ at the species level $(97 \%$ sequences identity) and $87 \%$ at the genus level $(95 \%$ sequence identity). The library coverage in SAB2b was lower, at 74 and $77 \%$ at the species and genus levels, respectively (Fig. S3 in the supplement).

\section{Abundance of specific Planctomycetes clades}

Three specific oligonucleotide probes were designed for the newly defined Planctomycetes clades. Along with a previously designed probe (Pizzetti et al. 2011), the 3 new probes targeted all 4 dominant clades identified in the Lago di Paola clone libraries (Table S2). Probe PirF85 is specific to the Pirellularelated group $F$, encompassing 7 of 8 sequences retrieved in the present study. Probe PirE62 is fully specific to 8 of 9 sequences of the Pirellula-related group E. Probe PlaS2114 targeted a monophyletic clade within the Planctomyces-related group A, which encompassed 10 of 31 sequences retrieved in the present study. Probe uPlaB440 was previously designed by Pizzetti et al. (2011) based on sequences retrieved from North Sea coastal waters. It targeted 11 of 15 sequences that belonged to the uncultured Planctomycetes group B.

The counts with probe PirF85 in the bottom waters of Lago di Paola were (mean \pm SD) $1.1 \pm 0.4 \times 10^{4} \mathrm{ml}^{-1}$ $(0.2 \pm 0.1 \%$ of prokaryotic picoplankton). In the surface water samples, only single PirF85-positive cells occurred, and the counts were below the detection limit of $0.1 \%$ (Fig. 6). The Pirellula-related group E, which was identified with probe PirE62, accounted for $1.2 \pm 0.5 \times 10^{4} \mathrm{ml}^{-1}(0.2 \pm 0.1 \%)$ and $2.0 \pm 0.5 \times 10^{4}$ $\mathrm{ml}^{-1}(0.3 \pm 0.1 \%)$ in the surface and bottom waters,

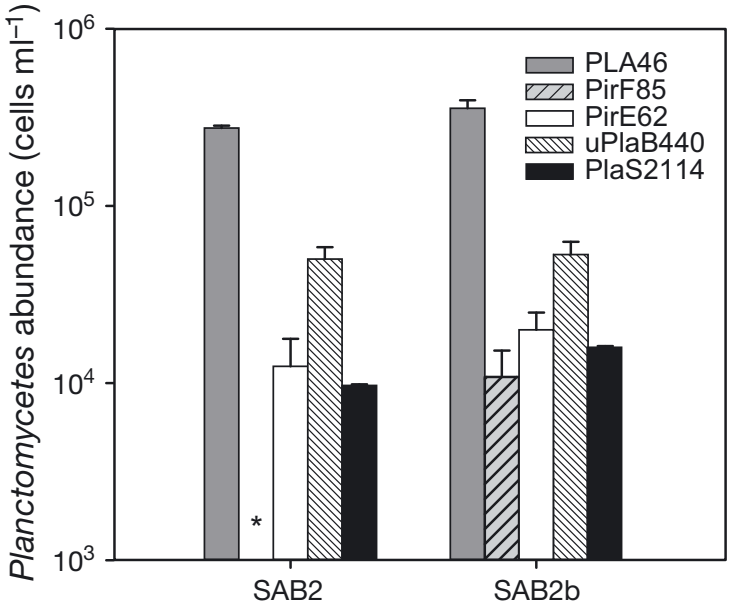

Fig. 6. Logarithmic scale (note that the $y$-axis does not start at zero) of absolute abundances of Planctomycetes (PLA46), Pirellula-related group F (PirF85), Pirellula-related group E (PirE62), uncultured Planctomycetes group B (uPlaB440) and Planctomyces-related group A (PlaS2114) on 15 September 2008. Means \pm SD of 3 replicates are shown. Data are from site SAB2 (see Fig. 1; surface [SAB2]; bottom [SAB2b]). ${ }^{*}$ : below detection level

respectively (Fig. 6). The number of cells hybridized with probe uPlaB440 was $5.0 \pm 0.8 \times 10^{4} \mathrm{ml}^{-1}(0.6 \pm$ $0.1 \%)$ at the surface and $5.3 \pm 1.0 \times 10^{4} \mathrm{ml}^{-1}(0.8 \pm$ $0.1 \%$ ) at the bottom (Fig. 6). Finally, probe PlaS2114 targeted $9.7 \pm 0.2 \times 10^{3}$ cells ml ${ }^{-1}(0.1 \%)$ and $1.6 \pm$ $0.03 \times 10^{4}$ cells ml ${ }^{-1}(0.2 \%)$ in the upper and lower water column of the lake (Fig. 6). Throughout the samples from 2008, the sum of the counts with the 4 clade-specific probes was 26 and $28 \%$ of the PLA46 counts at the surface and the bottom of the lake, respectively.

\section{DISCUSSION}

Before discussing the abundances of Planctomycetes in Lago di Paola in detail, the methodological evolution from FISH to CARD-FISH, which occurred during the course of this study, needs to be considered. Initially, Planctomycetes counts were higher with FISH than with CARD-FISH in the samples taken in 2003. Later, the opposite was true for the 2008 samples. We believe that this was probably due to a change in the sample fixation from a final concentration of $2 \%$ formaldehyde in 2003 to the lower concentration of $1 \%$ of paraformaldehyde that was used in 2008. Aldehydes are cross-linking amino groups. After fixation at $2 \%$, the $16 \mathrm{~S}$ rRNA of part of the Planctomycetes may no longer have been accessible to the large HRP-labeled probes used in CARDFISH, due to the larger size of the label $(\sim 44 \mathrm{kDa})$. 
The smaller Cy3-labeled probes (the molecular weight of $\mathrm{Cy} 3$ is $~ 700 \mathrm{Da}$ ) probably penetrated the cells in the 2003 samples more efficiently. The samples from 2008, however, were less cross-linked by the $1 \%$ paraformaldehyde fixative, and here CARDFISH was superior to FISH due to its greater sensitivity. We are confident that the counts obtained with the 2 methods for the 2 different sample types are reliable. With both methods we observed the doughnut-shaped hybridization pattern that is typical of Planctomycetes (Woebken et al. 2007a). If there was a counting bias, the Planctomycetes numbers were somewhat underestimated as opposed to overestimated.

Planctomycetes abundances in Lago di Paola were high. The abundance maximum of $1.5 \times 10^{6} \mathrm{cells} \mathrm{ml}^{-1}$ at SAB1 at the beginning of July 2003 is, to our knowledge, the highest value reported for a coastal system, exceeding previous reports by one order of magnitude (Morris et al. 2006, Alonso et al. 2010, Simonato et al. 2010). The values found by these authors are very similar to the maximum of $5 \times$ $10^{4} \mathrm{ml}^{-1}$ that we counted at the adjacent nearshore marine sampling site, SAB4. The exceptionally high abundances of Planctomycetes in Lago di Paola are probably due to the meso-eutrophic character of the lake, which receives high amounts of organic carbon from autochthonous (internal primary production) and allochthonous sources, such as agriculture.

Planctomycetes abundance correlated positively with chl $a$ and DOC, which are also positively correlated to each other (Table S4). A likely scenario is that a summer bloom of algae formed fresh substrate for the growth of the Planctomycetes. This further confirms earlier reports of high abundances of Planctomycetes being linked to algal blooms (Janse et al. 2000, Brümmer et al. 2004, Eiler \& Bertilsson 2004, Ward et al. 2006, Tadonléké 2007, Pizzetti et al. 2011).

The variation in Planctomycetes abundance could also be explained by the variance of DO. Lago di Paola is stratified during the summer. However, at the end of this season, when the waters begin to mix, the oxygen concentration dramatically decreases at the surface, leading to hypoxia throughout the entire water column (Fig. 3). At that time, Planctomycetes abundance was higher at the lake bottom than at the surface, suggesting that the Planctomycetes were strongly affected by the change from oxic to hypoxic conditions occurring in the surface water. Indeed, when oxygen saturation was re-established, an increase in Planctomycetes was registered. This, along with a similar diversity of Planctomycetes in the surface and bottom water libraries (SAB2 vs. SAB2b; Fig. 5), indicates that this phylum can deal with hypoxic conditions with an oxygen saturation of $\sim 12 \%$.

In accordance with previous studies (Chouari et al. 2003, Elshahed et al. 2007), we used primer Pla46F, which is specific to Planctomycetes, and the universal primer $1392 \mathrm{R}$ to analyze Planctomycetes $16 \mathrm{~S}$ rRNA diversity in Lago di Paola. Recently, Shu \& Jiao (2008b) suggested and tested a new primer set to amplify planctomycetal 16S rRNA genes from seawater, revealing that it retrieved a broader Planctomycetes diversity and less out-group sequences. Testing this primer set on our sequences demonstrated that it would have reduced the retrieval of non-Planctomycetes. However, it would have also underestimated the Planctomycetes diversity in our sample by not amplifying the 16S rRNA of the Planctomycetes-related group A. We conclude that the primer set we used was adequate, even if in the future it might be possible to design more specific primers that are based, for example, on PCRindependent metagenome libraries.

With our study, several new Planctomycetes phylotypes have been added to the database as almost fulllength 16S rRNA gene sequences. We were able to define 4 stable coastal groups by conducting a comparative sequence analysis. Sequences of all of the clades were retrieved from the surface and bottom waters of Lago di Paola, suggesting a high connectivity, which reflects mixing. Clone frequencies in the surface and bottom water libraries were similar except for the uncultured Planctomycetes group B, of which more sequences were obtained from the bottom water. However, this finding is unlikely to be significant, as the CARD-FISH counts for this group obtained with probe uPlaB440 were $\sim 5 \times 10^{4} \mathrm{ml}^{-1}$ in the surface as well as the bottom water. The cladespecific CARD-FISH counts with probes PirF85, PirE62, and PlaS2114 confirmed the simultaneous presence of all clades in the surface and bottom waters in similar abundances. None of the clades accounted for more than $1 \%$ of the total picoplankton in the samples examined. We cannot exclude the possibility that the 4 Planctomycetes clades examined herein might be more abundant in terms of particle numbers because this research was conducted on the $0.2-10 \mu \mathrm{m}$ fraction, which excluded aggregates.

The Pirellula-related group F clones obtained in this study were closely related to sequences retrieved from marine sediment and the surface of marine macroalgae. Most of the Pirellula-related group E sequences, however, were best affiliated with sequences 
retrieved from wastewater treatment plants, river biofilms and mangrove soils (Fig. 5). Our sequences from the Planctomyces-related group A currently have the highest identity ( $91 \%$ sequence identity) with sequences from compost leakage water, cold sulphurous springs and cold seep sediment (Fig. 5). Planctomyces brasiliensis, which also belongs to this clade, was isolated from a hypersaline lake in Brazil. The Planctomycetes-related group A clade seems to have a wide habitat range, whereas the uncultured Planctomycetes group B clade was first described by Pizzetti et al. (2011) in North Sea coastal waters. We have demonstrated that this group may be more widely distributed in coastal marine habitats. Interestingly, in addition to the common doughnut-shaped cells, probe uPlaB440 also visualized a second, rather rod-shaped morphotype, indicating the presence of distinct sub-populations (Fig. S4 in the supplement).

With this study we have not only increased our knowledge of Planctomycetes diversity, but have also produced 3 new clade-specific probes. Our data will facilitate future studies of the ecology and biogeography of the coastal marine clades of Planctomycetes.

Acknowledgements. We thank M. Manganelli, A. Puddu, A. Zoppini, M. Lupascu and S. Amafitano for the 2003 sampling campaign, and F. R. Olivetti for 2008 data collection. This study was funded by the Marie Curie Early Stage Training Site in Marine Microbiology (MarMic EST contract MEST-CT-2004-007776) and was supported by the International Max Planck Research School of Marine Microbiology (MarMic).

\section{LITERATURE CITED}

> Alonso C, Gómez-Pereira PR, Ramette A, Ortega L, Fuchs BM, Amann R (2010) Multilevel analysis of the bacterial diversity along the environmental gradient Río de la Plata-South Atlantic Ocean. Aquat Microb Ecol 61: $57-72$

> Amalfitano S, Fazi S, Zoppini A, Barra Caracciolo A, Grenni P, Puddu A (2008) Responses of benthic bacteria to experimental drying in sediments from Mediterranean temporary rivers. Microb Ecol 55:270-279

Bauld J, Staley JT (1976) Planctomyces maris sp. nov.: a marine isolate of Planctomyces-Blastocaulis group of budding bacteria. J Gen Microbiol 97:45-55

> Brümmer IHM, Felske ADM, Wagner-Döbler I (2004) Diversity and seasonal changes of uncultured Planctomycetales in river biofilms. Appl Environ Microbiol 70:5094-5101

> Chouari R, Le Paslier D, Daegelen P, Ginestet P, Weissenbach J, Sghir A (2003) Molecular evidence for novel planctomycete diversity in a municipal wastewater treatment plant. Appl Environ Microbiol 69:7354-7363

Crump BC, Armbrust EV, Baross JA (1999) Phylogenetic analysis of particle-attached and free-living bacterial communities in the Columbia River, its estuary, and the adjacent coastal ocean. Appl Environ Microbiol 65:3192-3204
DeLong EF, Franks DG, Alldredge AL (1993) Phylogenetic diversity of aggregate-attached vs. free-living marine bacterial assemblages. Limnol Oceanogr 38:924-934

Eiler A, Bertilsson S (2004) Composition of freshwater bacterial communities associated with cyanobacterial blooms in four Swedish lakes. Environ Microbiol 6:1228-1243

> Elshahed MS, Youssef NH, Luo QW, Najar FZ and others (2007) Phylogenetic and metabolic diversity of Planctomycetes from anaerobic, sulfide and sulfur-rich Zodletone Spring, Oklahoma. Appl Environ Microbiol 73: 4707-4716

Fieseler L, Horn M, Wagner M, Hentschel U (2004) Discovery of the novel candidate phylum 'Poribacteria' in marine sponges. Appl Environ Microbiol 70:3724-3732

> Franzmann PD, Skerman VBD (1984) Gemmata obscuriglobus, a new genus and species of the budding bacteria. Antonie van Leeuwenhoek 50:261-268

Fuerst JA (1995) The planctomycetes: emerging models for microbial ecology, evolution and cell biology. Microbiology 141:1493-1506

Fuerst JA (2005) Intracellular compartmentation in Planctomycetes. Annu Rev Microbiol 59:299-328

Fukunaga Y, Kurahashi M, Sakiyama Y, Ohuchi M, Yokota A, Harayama S (2009) Phycisphaera mikurensis gen. nov., sp. nov., isolated from a marine alga, and proposal of Phycisphaeraceae fam. nov., Phycisphaerales ord. nov. and Phycisphaerae classis nov. in the phylum Planctomycetes. J Gen Appl Microbiol 55:267-275

Giovannoni SJ, Schabtach E, Castenholz RW (1987) Isosphaera pallida, gen. and comb. nov., a gliding, budding eubacterium from hot-springs. Arch Microbiol 147: 276-284

Glöckner FO, Amann R, Alfreider A, Pernthaler J, Psenner R, Trebesius K, Schleifer KH (1996) An in situ hybridization protocol for the detection and identification of planktonic bacteria. Syst Appl Microbiol 19: 403-406

> Glöckner FO, Kube M, Bauer M, Teeling $\mathrm{H}$ and others (2003) Complete genome sequence of the marine planctomycete Pirellula sp. strain 1. Proc Natl Acad Sci USA 100:8298-8303

Good IJ (1953) The population frequencies of species and the estimation of population parameters. Biometrika 40: $237-264$

> Inagaki F, Nunoura T, Nakagawa S, Teske A and others (2006) Biogeographical distribution and diversity of microbes in methane hydrate-bearing deep marine sediments, on the Pacific Ocean margin. Proc Natl Acad Sci USA 103:2815-2820

Janse I, Zwart G, van der Maarel MJEC, Gottschal JC (2000) Composition of the bacterial community degrading Phaeocystis mucopolysaccharides in enrichment cultures. Aquat Microb Ecol 22:119-133

Kalyuzhnaya MG, Lidstrom ME, Chistoserdova L (2004) Utility of environmental primers targeting ancient enzymes: methylotroph detection in Lake Washington. Microb Ecol 48:463-472

Kalyuzhnaya MG, Nercessian O, Lidstrom ME, Chistoserdova L (2005) Development and application of polymerase chain reaction primers based on $f h c D$ for environmental detection of methanopterin-linked C1-metabolism in bacteria. Environ Microbiol 7:1269-1274

$>$ Kemp PF, Aller JY (2004) Bacterial diversity in aquatic and other environments: what 16S rDNA libraries can tell us. FEMS Microbiol Ecol 47:161-177 
Kulichevskaya IS, Ivanova AO, Belova SE, Baulina OI and others (2007) Schlesneria paludicola gen. nov., sp. nov., the first acidophilic member of the order Planctomycetales, from Sphagnum-dominated boreal wetlands. Int J Syst Evol Microbiol 57:2680-2687

Kulichevskaya IS, Ivanova AO, Baulina OI, Bodelier PLE, Damste JSS, Dedysh SN (2008) Singulisphaera acidiphila gen. nov., sp. nov., a non-filamentous, Isosphaera-like planctomycete from acidic northern wetlands. Int J Syst Evol Microbiol 58:1186-1193

Kulichevskaya IS, Baulina OI, Bodelier PLE, Rijpstra WIC, Damste JSS, Dedysh SN (2009) Zavarzinella formosa gen. nov., sp. nov., a novel stalked, Gemmata-like planctomycete from a Siberian peat bog. Int J Syst Evol Microbiol 59:357-364

Lane DJ (1991) 16S/23S rRNA sequencing. In: Stackebrandt E, Goodfellow M (eds) Nucleic acid techniques in bacterial systematics. John Wiley \& Sons, New York, NY, p 115-175

Legendre P, Legendre L (1998) Numerical ecology, 2nd English edn. Elsevier, Amsterdam

> Lindsay MR, Webb RI, Fuerst JA (1997) Pirellulosomes: a new type of membrane-bounded cell compartment in planctomycete bacteria of the genus Pirellula. Microbiology 143:739-748

Lindsay MR, Webb RI, Strous M, Jetten MS, Butler MK, Forde RJ, Fuerst JA (2001) Cell compartmentalisation in planctomycetes: novel types of structural organisation for the bacterial cell. Arch Microbiol 175:413-429

Llobet-Brossa E, Rossello-Mora R, Amann R (1998) Microbial community composition of Wadden Sea sediments as revealed by fluorescence in situ hybridization. Appl Environ Microbiol 64:2691-2696

> Lorenzen CJ (1967) Determination of chlorophyll and pheopigments: spectrophotometric equations. Limnol Oceanogr 12:343-346

Ludwig W, Strunk O, Westram R, Richter L and others (2004) ARB: a software environment for sequence data. Nucleic Acids Res 32:1363-1371

Manganelli M (2005) Sviluppo di criteri di valutazione del rischio ambientale e sanitario associato a microrganismi patogeni in ambienti acquatici. Final Report ISPELS Project, Roma

Mevik BH, Wehrens R (2007) The pls package: principal component and partial least squares regression in $\mathrm{R}$. J Stat Softw 18:1-24

> Miskin IP, Farrimond P, Head IM (1999) Identification of novel bacterial lineages as active members of microbial populations in a freshwater sediment using a rapid RNA extraction procedure and RT-PCR. Microbiology 145: 1977-1987

> Morris RM, Longnecker K, Giovannoni SJ (2006) Pirellula and OM43 are among the dominant lineages identified in an Oregon coast diatom bloom. Environ Microbiol 8:1361-1370

Musat N, Werner U, Knittel K, Kolb S and others (2006) Microbial community structure of sandy intertidal sediments in the North Sea, Sylt-Rømø Basin, Wadden Sea. Syst Appl Microbiol 29:333-348

Neef A, Amann R, Schlesner H, Schleifer KH (1998) Monitoring a widespread bacterial group: in situ detection of planctomycetes with 16S rRNA-targeted probes. Microbiology 144:3257-3266

Parsons TR, Maita Y, Lalli CM (1984) A manual of chemical and biological methods for seawater analysis. Pergamon Press, Oxford
Peplies J, Kottmann R, Ludwig W, Glöckner FO (2008) A standard operating procedure for phylogenetic inference (SOPPI) using (rRNA) marker genes. Syst Appl Microbiol 31:251-257

> Pernthaler A, Pernthaler J, Amann R (2002) Fluorescence in situ hybridization and catalyzed reporter deposition for the identification of marine bacteria. Appl Environ Microbiol 68:3094-3101

Pernthaler A, Pernthaler J, Amann R (2004) Sensitive multi-color fluorescence in situ hybridization for the identification of environmental microorganisms. In: Kowalchuk G, de Bruijn FJ, Head IM, Akkermans ADL, van Elsas JD (eds) Molecular microbial ecology manual, 2nd edn. Kluwer Academic Publishers, Dordrecht, p 711-726

Pettine M, Patrolecco L, Manganelli M, Capri S, Farrace MG (1999) Seasonal variations of dissolved organic matter in the northern Adriatic Sea. Mar Chem 64:153-169

Pizzetti I, Fuchs BM, Gerdts G, Wichels A, Wiltshire $\mathrm{KH}$, Amann R (2011) Temporal variability of coastal Planctomycetes clades at Kabeltonne station, North Sea. Appl Environ Microbiol 77:5009-5017

> Polz MF, Cavanaugh CM (1998) Bias in template-to-product ratios in multitemplate PCR. Appl Environ Microbiol 64: 3724-3730

Pruesse E, Quast C, Knittel K, Fuchs BM, Ludwig W, Peplies J, Glöckner FO (2007) SILVA: a comprehensive online resource for quality checked and aligned ribosomal RNA sequence data compatible with ARB. Nucleic Acids Res 35:7188-7196

R Development Core Team (2009) R: A language and environment for statistical computing. R Foundation for Statistical Computing, Vienna. www.r-project.org

Rath J, Wu KY, Herndl GJ, DeLong EF (1998) High phylogenetic diversity in a marine-snow-associated bacterial assemblage. Aquat Microb Ecol 14:261-269

Rosselló-Mora R, Amann R (2001) The species concept for prokaryotes. FEMS Microbiol Rev 25:39-67

Rusch A, Huettel M, Reimers CE, Taghon GL, Fuller CM (2003) Activity and distribution of bacterial populations in Middle Atlantic Bight shelf sands. FEMS Microbiol Ecol 44:89-100

Schlesner H (1994) The development of media suitable for the microorganisms morphologically resembling Planctomyces spp., Pirellula spp., and other Planctomycetales from various aquatic habitats using dilute media. Syst Appl Microbiol 17:135-145

> Schloss PD, Handelsman J (2005) Introducing DOTUR, a computer program for defining operational taxonomic units and estimating species richness. Appl Environ Microbiol 71:1501-1506

Shu QL, Jiao NZ (2008a) Different Planctomycetes diversity patterns in latitudinal surface seawater of the open sea and in sediment. J Microbiol 46:154-159

Shu QL, Jiao NZ (2008b) New primers for amplification of the Planctomycetes 16S rRNA gene from environmental samples. J Rapid Meth Automat Microbiol 16:330-336

> Shu QL, Jiao NZ (2008c) Profiling Planctomycetales diversity with reference to anammox-related bacteria in a South China Sea, deep-sea sediment. Mar Ecol 29: 413-420

Simonato F, Gómez-Pereira PR, Fuchs BM, Amann R (2010) Bacterioplankton diversity and community composition in the Southern Lagoon of Venice. Syst Appl Microbiol $33: 128-138$ 
Strous M, Fuerst JA, Kramer EHM, Logemann S and others (1999) Missing lithotroph identified as new planctomycete. Nature 400:446-449

Suzuki MT, Giovannoni SJ (1996) Bias caused by template annealing in the amplification of mixtures of 16S rRNA genes by PCR. Appl Environ Microbiol 62:625-630

Tadonléké RD (2007) Strong coupling between natural Planctomycetes and changes in the quality of dissolved organic matter in freshwater samples. FEMS Microbiol Ecol 59:543-555

Valderrama JC (1981) The simultaneous analysis of total nitrogen and total phosphorus in natural waters. Mar Chem 10:109-122

Vergin KL, Urbach E, Stein JL, DeLong EF, Lanoil BD, Giovannoni SJ (1998) Screening of a fosmid library of marine environmental genomic DNA fragments reveals four clones related to members of the order Planctomycetales. Appl Environ Microbiol 64:3075-3078

Wagner M, Horn M (2006) The Planctomycetes, Verrucomicrobia, Chlamydiae and sister phyla comprise a superphylum with biotechnological and medical relevance. Curr Opin Biotechnol 17:241-249

Wallner G, Amann R, Beisker W (1993) Optimizing fluorescent in situ hybridization with rRNA-targeted oligonucleotide probes for flow cytometric identification of microorganisms. Cytometry 14:136-143

Wang J, Jenkins C, Webb RI, Fuerst JA (2002) Isolation of Gemmata-like and Isosphaera-like planctomycete bacteria from soil and freshwater. Appl Environ Microbiol 68: 417-422

Ward N, Staley JT, Fuerst JA, Giovannoni S, Schlesner H,

Editorial responsibility: Jed Fuhrman,

Los Angeles, California, USA
Stackebrandt E (2006) The order Planctomycetales, including the genera Planctomyces, Pirellula, Gemmata and Isophaera and the Candidatus genera Brocadia, Kuenenia and Scalindua. In: Dworkin M, Falkow S, Rosenberg E, Schleifer K-H, Stackebrandt E (eds) The Prokaryotes, a handbook on the biology of bacteria, 3rd edn. Vol 7: Proteobacteria: Delta and Epsilon subclasses. Springer, New York, NY, p 757-793

Winkelmann N, Harder J (2009) An improved isolation method for attached-living Planctomycetes of the genus Rhodopirellula. J Microbiol Methods 77:276-284

Woebken D, Fuchs BM, Kuypers MMM, Amann R (2007a) Potential interactions of particle-associated anammox bacteria with bacterial and archaeal partners in the Namibian upwelling system. Appl Environ Microbiol 73:4648-4657

> Woebken D, Teeling H, Wecker P, Dumitriu A and others (2007b) Fosmids of novel marine Planctomycetes from the Namibian and Oregon coast upwelling systems and their cross-comparison with planctomycete genomes. ISME J 1:419-435

> Wold S, Sjöström M, Eriksson L (2001) PLS-regression: a basic tool of chemometrics. Chemom Intell Lab Syst 58: 109-130

Xu KD, Stewart PS, Xia F, Huang CT, McFeters GA (1998) Spatial physiological heterogeneity in Pseudomonas aeruginosa biofilm is determined by oxygen availability. Appl Environ Microbiol 64:4035-4039

Zhou J, Bruns MA, Tiedje JM (1996) DNA recovery from soils of diverse composition. Appl Environ Microbiol 62: $316-322$

Submitted: November 4, 2010; Accepted: August 23, 2011 Proofs received from author(s): November 11, 2011 